\title{
1 Management of solar energy to power electrochemical wastewater
}

\section{2 treatments.}

3 M. Millán, C.M. Fernández-Marchante, J. Lobato, P. Cañizares, M.A. Rodrigo*

4 Department of Chemical Engineering, Faculty of Chemical Sciences \& Technologies,

5 University of Castilla-La Mancha, Av. Camilo Jose Cela n 12, 13071 Ciudad Real, Spain

\section{Abstract}

7 In this work, the management of photovoltaic (PV) energy, assisted by a redox flow 8 battery (RFB), for powering an electrochemical advanced oxidation process (EAOP), is 9 evaluated. The storage of surplus energy allows to extend the treatment time overnight and to increase the environmental remediation efficiency during the whole electrochemical treatment. Nevertheless, this work points out that it is important to evaluate the most suitable powering strategy to take advantage of the total solar energy produced. The energy supplied by the PV panels to each system depends on the electrical features of the electrochemical devices (electrooxidation reactor and the RFB) and, especially, on the connection between them (series or parallel). A straightforward coupling (without a targeted regulation of the energy distributed between the EAOP and the RFB) brings out a time-depending and uncontrolled powering. This type of strategy opposes to the smarter regulation of the energy between the EAOP and the RFB by means of a targeted powering to each device. Results show higher remediation degrees when both electrochemical devices are directly coupled in parallel, regardless of the operational mode used (straightforward or targeted) due to lower current densities lead to higher global performances for both electrochemical devices. Nonetheless, it is important to note that the green targeted powering notices higher remediations than the straightforward coupling when the system operates under parallel connection and a RFB control. The 

lower current densities supplied to the RFB point out higher capacities and, consequently, extend the remediation treatment. Those results shed light on interesting conclusions in terms of green energy use. Furthermore, this software tool allows by means of a simple predictive modelling to optime the operational conditions of electrochemical treatments powered by renewable energies and assisted by energy storage systems.

\section{Keywords}

Energy management; solar photovoltaic; electrochemical advanced oxidation processes; redox flow batteries; simulation

\section{Highlights}

- Coupling of PV to RFB and EAOPs extends the duration of treatment.

- Coupling of PV to RFB and EAOPs increases the total remediation degree reached.

- Lower current densities show higher remediation degrees per unit of energy supplied.

- Lower current densities allow to store a large amount of energy.

- Parallel electrical distributions allow to work under efficient operational conditions.

*Corresponding author. Telf: +34 926295 300; fax: +34 926295 256. E-mail address: 
The prevention and reversion of the climate change is, nowadays, one of the main targets of the research community. To overcome the environmental risks that we are facing, the society must learn new sustainable habits. Environmental protection, social cohesion and economic development constitute the three key elements of sustainability [1]. According to that, the term sustainable development was defined as "meeting the needs of the present without compromising the ability of the future generations to meet their own needs" [2].

Despite new generations are becoming aware of taking care of the environment, the past uncontrolled industrial and human activities have left high levels of pollution in natural sources including soils and water bodies that may contain hazardous concentrations of persistent organic pollutants (POPs) that should be removed to avoid harmful environmental and human risks.

The electrochemical techniques have been proved as one of the most suitable technologies to recover natural sources polluted by a wide range of compounds [3-7]. These processes have been outlined as clean, flexible and powerful, not only for treating wastewater, gases or soils but also for providing drinking water, even from low quality sources $[8,9]$. Furthermore, it is important to note that those treatments only require electrical energy to operate. Focusing on the treatment of wastewater, electrolyzers equipped with different electrodes materials (platinum, graphite, diamond, mixed metal oxide, metallic dioxide, etc. [10-12]) have demonstrated to be able to promote high degrees of mineralization, as a consequence of the generation of hydroxyl radicals [13], being the diamond one of the most active materials to undergo electrochemical advanced oxidation processes (EAOPs). The conductive diamond electrochemical oxidation (CDEO) has been widely applied by 
Until now, researchers have aimed their studies at developing efficient technologies capable of recovering affected natural resources, without paying attention to the possible adverse effects of the treatment [22]. Nevertheless, it is essential to strike a balance between efficiency and sustainability when a new treatment is studied to prevent an additional pollution source. Thus, keeping in mind the critical environmental emergency that the humankind must address, and the need for a sustainable development, the concept of green remediation arose. This idea is focused on the recovery of natural sources under the lowest environmental impact [23, 24]. Within this concept, the coupling of electrochemical technologies with renewable energies (REs) could turn these promising treatments into more environmentally friendly processes. It is worth mentioning that electrochemical technologies can be powered indistinctly by the grid or by renewable sources $[25,26]$ and this later strategy makes them the perfect tandem to get a green remediation. It is worth mentioning that electrochemical technologies can be directly powered by solar panels (Off-grid installations) using direct current (DC) [27]. This operational strategy does not require the use of inverter devices which increases the cost of the remediation setup and its operational management. Furthermore, these characteristics make this operational strategy suitable to be installed in remote areas without energy supply. The use of photovoltaic (PV) energy to power electrochemical treatments has been widely reported in literature, showing promising remediation results [28-34]. Nevertheless, the intermittency and unpredictability that characterize the solar power, increase the treatment time and reduces its efficiency, due to the fluctuating current supplied 
throughout a day [33]. Despite those negatives operational features, a green powering may be environmental and economically attractive to recover natural sources [35].

It has been proved that the use of green energy may work as only power source of batch treatments. Nevertheless, the drawbacks of green energies rule a continuous operation out. To solve this problem, many groups have tested the performance of electrochemical remediation technologies directly coupled with traditional batteries (Lead-acid batteries) directly charged by green energies [36-39]. Nevertheless, a direct powering by batteries may lead to a huge waste of energy due to the efficiencies of energy conversion. To streak a balance between both operational conditions, the use of REs and ESSs under targeted operational conditions is proposed.

The control of the current supplied to the electrooxidation treatment avoids undesired reactions, improves the current efficiency, and reduces the energy costs [32]. Simultaneously, the storage of exceeding power (typically at midday), by means of ESS working as peak shaving (or load leveling) devices, helps to fit the production and demand of renewable energy [40, 41]. Regarding the ESSs, redox flow batteries (RFBs) have shown promising characteristics regarding other more traditional batteries. The main advantage of the RFBs is that power and energy are independent [42, 43]. This feature provides the RFBs with a high flexibility and allows a straightforward scalability which make easier its coupling to electrochemical technologies. Furthermore, they can directly be powered by renewable energies reaching high storage capacities and efficiencies [44, 45]. Thereby, both strategies promote a smother powering, which may turn into efficient remediation treatments.

Mathematical models can provide a critical insight into treatment remediation and can work as guide of corrective and preventive actions [46]. Furthermore, these modelling tools may help to improve the electrochemical designs [41] and to assess the best 
operational conditions. The modelling of electrooxidation treatments has been widely assessed [47-51]. Those studies allow to know in detail the behaviour of remediation treatments under different operational conditions. Nonetheless, to the best of our knowledge, studies about the transient response at non-galvanostatic operational mode have not been performed yet.

In view of the aforementioned background, the main aim of this work is to test a software tool capable of predicting the degree of remediation reached by an EAOP treatment powered by a combined solar photovoltaic panel and an RFB. Thus, in one of the strategies, the energy produced by the PV panels is straightforwardly used in an electrochemical treatment and stored in an RFB. In turn, the stored energy is powered to the environmental treatment overnight. Alternatively, other strategy consisting of the targeted distribution of solar energy to the EAOP and RFB. In both cases, the energy distribution between both electrochemical devices (EAOP treatment and redox flow battery) was assessed using different electrical configurations, series and parallel connections, and in three different sunlight profiles corresponding to different seasons of the year. Thus, the best powering strategy was determined according to the highest remediation reached per unit of energy supplied, which it is a very important milestone in the search of more sustainable electrochemical advanced oxidation processes for the treatment of wastewater.

\section{Materials and methods}

The current density applied highly influences the efficiency of electrochemical remediation treatments [52]. The direct coupling of an electrochemical advanced oxidation process (EAOP), such electro-oxidation, with a PV panel does not allow to work under optimum operational conditions because of the fluctuating solar radiations received throughout a day $[53,54]$. 
To record and monitor the variables of a treatment is essential to ensure its control and efficiency [55]. Furthermore, to optimize the control of a treatment may bring out operational cost drop and effluent quality increases [56]. Therefore, the control of the energy produced by a PV panel to power an electro-oxidation treatment is essential to reach the most efficient remediation.

To overcome this drawback, energy storage systems may be coupled. These devices can provide a smoother powering to the EAOP treatment. Thus, a uniform and more efficient remediation may be carried out. To test this hypothesis, in this work it is simulated the coupling of a vanadium redox flow battery with an EAOP, with the aim of storing the exceeding energy of PV panels at peak hours and powering it at lower or null green power production hours. To perform this simulation, the mathematical modelling of both devices (EAOP and RFB) carried out in a previous study was used. The formulated and tested models were integrated using a simple programming language in Visual Basic and they can be found elsewhere [57]. The fixed parameters of this predictive software tool are related to the specifications of the experimental setups and the variable parameters are the energy flow and the concentration of species which directly depend on the solar radiation received. This model was carried out using experimental bench scale setups coupled with a PV plant made up of two solar panel $\left(1.313 \mathrm{~m}^{2}\right.$ each panel) connected in parallel and supplied by ATERSA (Spain). An electrooxidation reactor, DiaCell@ 101, provided by Adamant Technologies (Switzerland) and equipped with boron doped diamond (BDD) electrodes $\left(75.8 \mathrm{~cm}^{2}\right)$ supplied by WaterDiam (France) was used as continuous electrochemical remediation system. Furthermore, a homemade vanadium redox flow battery (VRFB) made up of 4 single cells $\left(48 \mathrm{~cm}^{2}\right.$ each cell) connected in series was used as electrochemical energy storage system. The RFB operate at $50 \mathrm{~mL}$ $\min ^{-1}$ using $500 \mathrm{~mL}$ of electrolyte solution $\left(1.6 \mathrm{~mol} \mathrm{dm}{ }^{-3}\right.$ of $\mathrm{V}^{+\mathrm{n}}, 50: 50 \mathrm{VO}^{2+}$ and $\left.\mathrm{V}^{3+}\right)$. 
Figure 1 shows a scheme of the modelling software tool which represents the devices that

made up the remediation setup. The modelling was carried out considering a synthetic wastewater effluent polluted with $100 \mathrm{mg} \mathrm{dm}^{-3}$ of clopyralid and containing $3 \mathrm{~g} \mathrm{dm}^{-3}$ of

$\mathrm{Na}_{2} \mathrm{SO}_{4}$ as supporting electrolyte. These conditions provide the solution of an initial $\mathrm{pH}$ of $3.51 \pm 0.19$ and an initial conductivity of $4.03 \pm 0.22 \mathrm{mS} \mathrm{cm}^{-1}$. In addition, it is important to take into account that each PV module has an efficiency of $12.14 \%$ according to its technical specifications and the experimental energy efficiency reached by the homemade RFB was around $70 \%$.

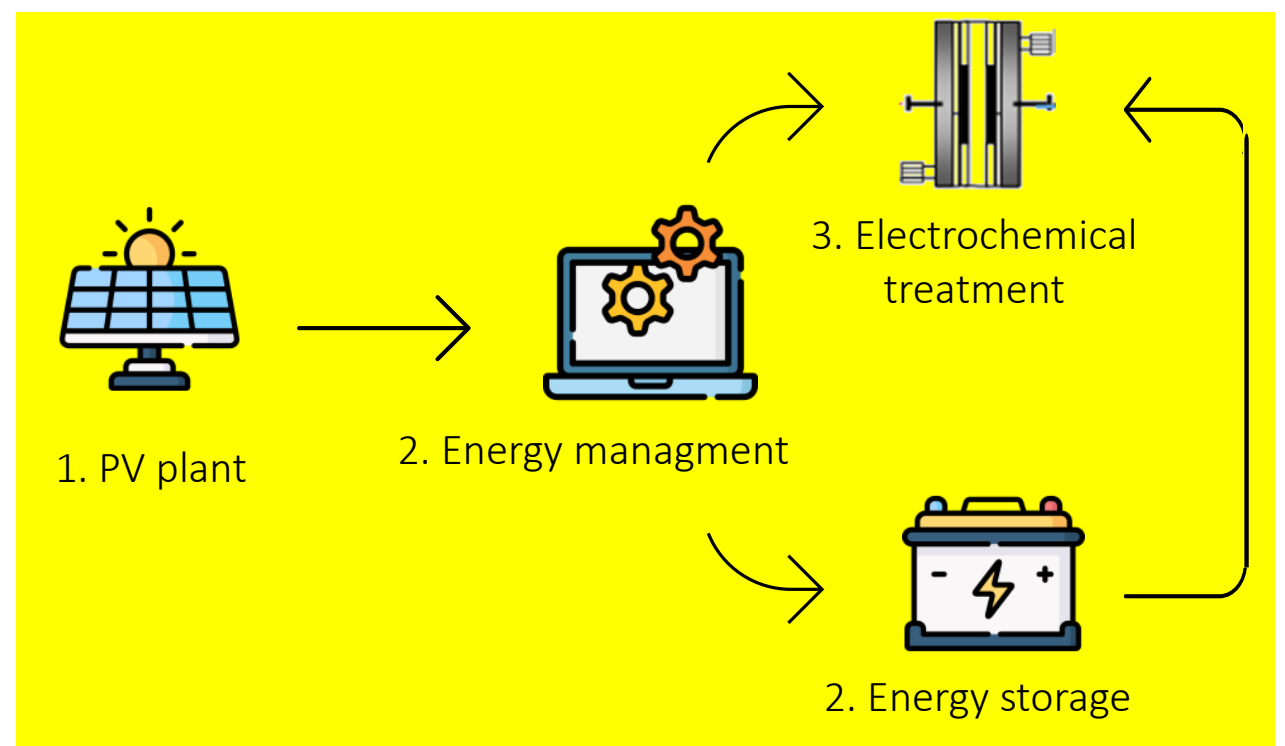

Figure 1. Scheme of the modelling software tool.

It is worth mentioning that the energy distribution that takes place when two electrochemical devices are coupled is different, according to the electrical connection between them. Furthermore, it is important to note that the energy supplied to each device directly depends on the overpotentials of each system and they cannot be controlled. Considering those facts, a targeted powering must be applied to manage and regulate properly the energy supplied to the treatment trying to achieve the most efficient remediation. To assess the most suitable electrical connection, several simulation tests were proposed. Figure 2 shows the electrical circuits that represent the different electrical 
connections that could be conducted between two electrochemical devices directly coupled to a PV plant by means of straightforward or targeted powerings. As Figure 1 shows, the electrical connection between both electrochemical devices may be performed under series or parallel configurations. The energy supplied under a straightforward powering will be distributed according to the internal resistances and overpotentials of each device. This distribution will depend on the curves, current-voltage, modelled in a previous work [57]. In contrast, the targeted strategy allows to regulate the energy supplied to each device by means of a variable resistance. Thus, if the variable resistance takes a value of cero, the total solar power will be divided into the EAOP and the RFB, according to a straightforward powering. Conversely, the higher is the current drop induced, the lower is the current supplied to this device. The current distribution will vary according to the electrical configuration as Kirchhoff laws expose $[58,59]$. For series circuits, the total potential is the sum of the voltages of each element of the circuit (Equation 1 and 2). By contrast, in parallel circuits, the voltage is the same in all the element into a node (Equation 3 and 4). The resolution procedure is detailed in the Supplementary Material section.

$$
\mathrm{I}_{\mathrm{PV}}=\mathrm{I}_{\mathrm{EAOP}}+\mathrm{I}_{\mathrm{RFB}}
$$

210 According to the previous equations, the series connection allows to power the 211 electrochemical devices at higher current densities. However, this may arise operational 212 drawbacks. Regarding electrochemical remediation treatments, higher currents can 213 involve higher mass transfer limitations [60], because they may turn into parasitic 
214 secondary reactions and an efficiency drop [11, 61, 62]. Regarding the RFB charge,

215 higher current densities bring out lower capacities and lower state of charge [63, 64].

216 Consequently, low power could be stored by the system.

217 Considering those premises, both electrochemical devices have an optimum overall 218 performance working at lower current densities. Thus, in order to operate under smother powering conditions capable of suppling lower current densities to the electrochemical systems, a regulated strategy was proposed. To do that, different resistances were tested with the aim of establishing the most suitable energy management strategy. In contrast to

222 the energy distribution previously described, in this case some features arise due to the 223 inclusion of a new resistance. The resistance simulates a current drop of 25, 50 and $75 \%$.

224 Equation 5 to 8 show the distribution of current, under series and parallel connections, by means of a EAOP or RFB current control.

RFB control:

$$
\mathrm{I}_{\mathrm{PV}}=\mathrm{I}_{E A O P}=\left(\frac{V_{R F B}}{R}\right)+\mathrm{I}_{\mathrm{RFB}}
$$

RFB control:

$$
\mathrm{I}_{\mathrm{PV}}=\mathrm{I}_{\mathrm{EAOP}}+\mathrm{I}_{\mathrm{RFB}}+\left(\frac{V_{R F B}}{R}\right)
$$




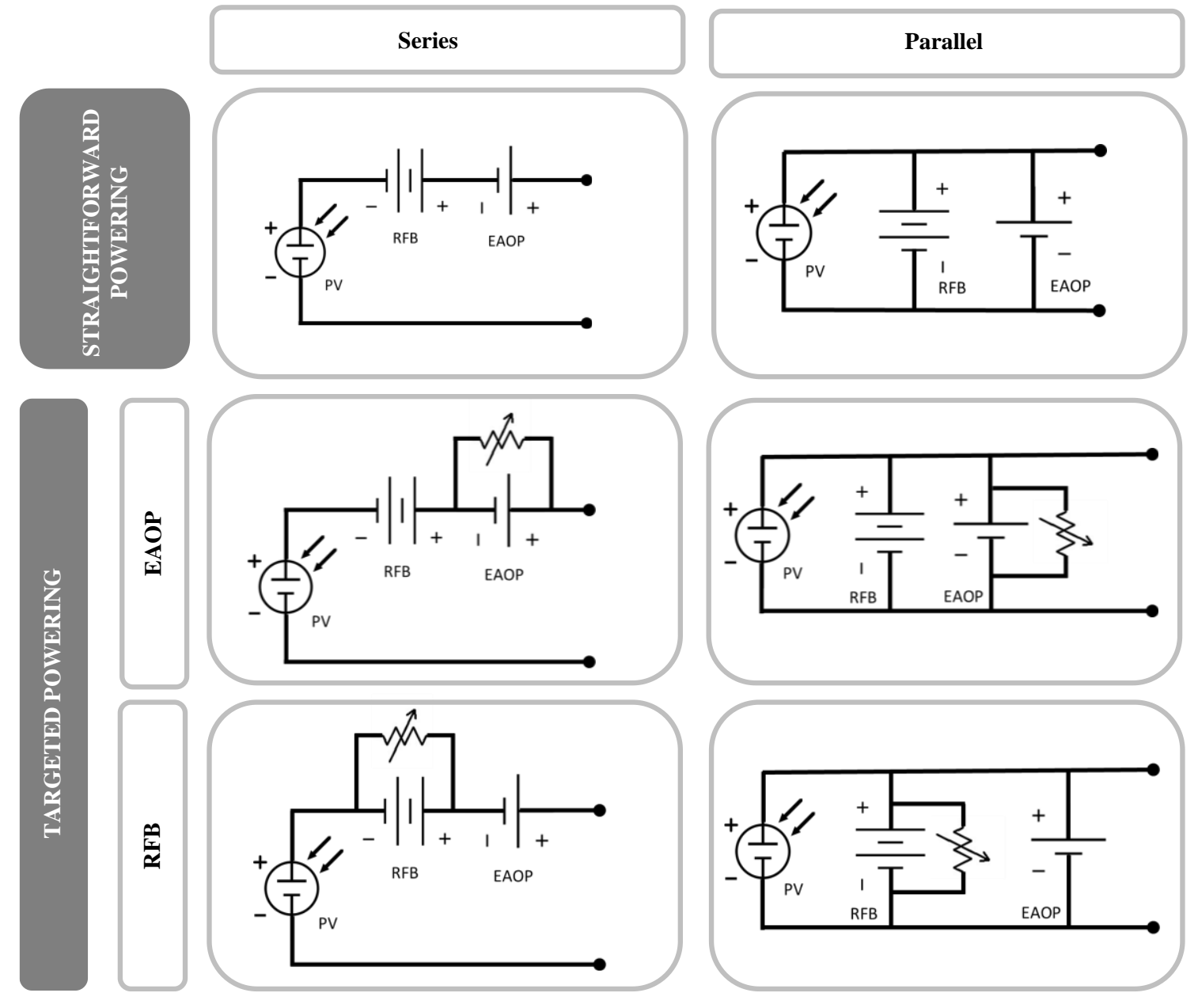

Figure 2. Experimental prediction planning. Photovoltaic solar electrochemical oxidation

235 under straightforward and targeted electrical powering.

236 To test this approach, the remediation of a persistent organic pollutant, clopyralid, was

237 evaluated according to the proposed electrical connection and considering the models

238 described elsewhere [57]. Furthermore, this study was performed using three different

239 solar profiles with the aim of assessing the efficiency of an assisted photovoltaic solar

240 electrochemical oxidation (PSEO) treatment under different weather conditions. Figure 3

241 shows the three different solar radiation patterns used, which correspond to typical days

242 in our location $(3.59 \mathrm{~N} 3.55 \mathrm{O})$ during the months of January, April and July, representing

243 different weather conditions within a year. 

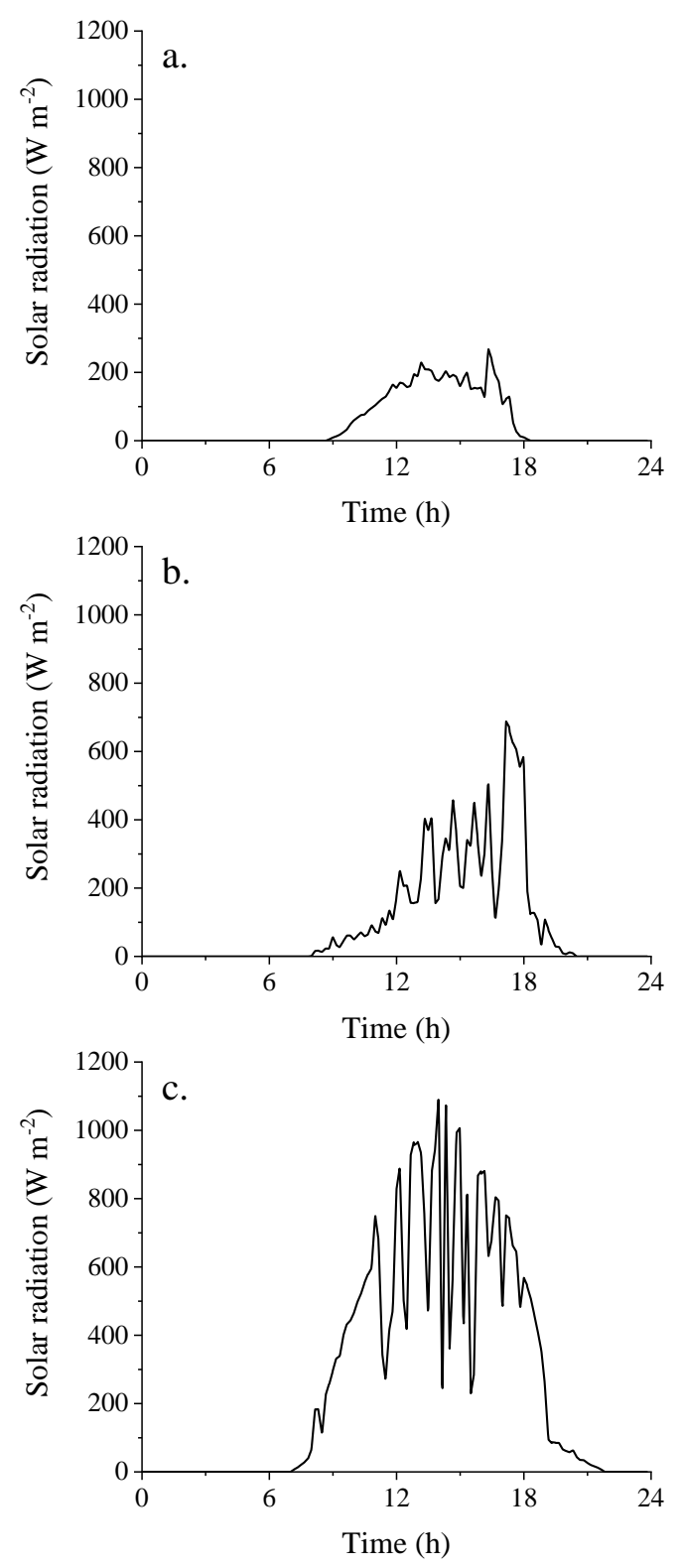

245 Figure 3. Solar radiation profiles for three cases of study with different radiation 246 intensities. Case (a) January, Case (b) April and Case (c) July. Location: Ciudad Real 247 (3.59 N 3.55 O), Spain.

248 The average solar radiation received was $51.45,102.62,274.28 \mathrm{~W} \mathrm{~m}^{-2}$ in January, April 249 and July, respectively. As expected, the winter day reported the lower total and average 250 values. Conversely, the sunny day noticed the maximum solar radiation values. It is 251 important to highlight the lower solar radiation recorded during the first hour of Case (b) 
regarding Case (a). These differences can be due to earlier cloud covers related to cloudy or rainy days (highly likely in spring).

\section{Results and discussion}

According to the powering strategies proposed and considering the simulation of the models formulated and validated in a previous work of our group [57], the degradation of clopyralid was evaluated for the different powering strategies proposed. Figure 4 shows the current supplied by the PV panels to each electrochemical device under a straightforward series and parallel powering and the current supplied by the RFB to the EAOP at night. As expected, the current supplied by the PV plant to the EAOP and the RFB is the same when the electrochemical devices are connected in series. Conversely, the use of a parallel connection produces a different electric current distribution, as Equation 4 details. Thus, the total current supplied by the PV plant is the sum of the current powered to the EAOP and the RFB.

It is worth mentioning that the current supplied to the RFB drops to zero when the battery reaches the full state of charge and, thus, once the battery is completely charged, the total solar power is sent to the EAOP. According to that, the RFB remains under open circuit potential (OCP) until the discharge step takes place. At that moment, the RFB works as power supply of the EAOP. Concerning voltage, the voltage supplied by the PV panel will follow the opposite trend than the current regarding Kirchhoff law. Figure 5 shows the voltage profiles of each device.

As expected, faster charge steps are observed when the system is powered under a series configuration due to the higher currents supplied to both electrochemical devices. Despite the charge of the battery can be performed faster at higher current densities, capacity 
275 losses may be observed as a consequence of air oxidation, gassing side reactions,

276 vanadium crossover and electrolyte unbalance issues $[65,66]$.
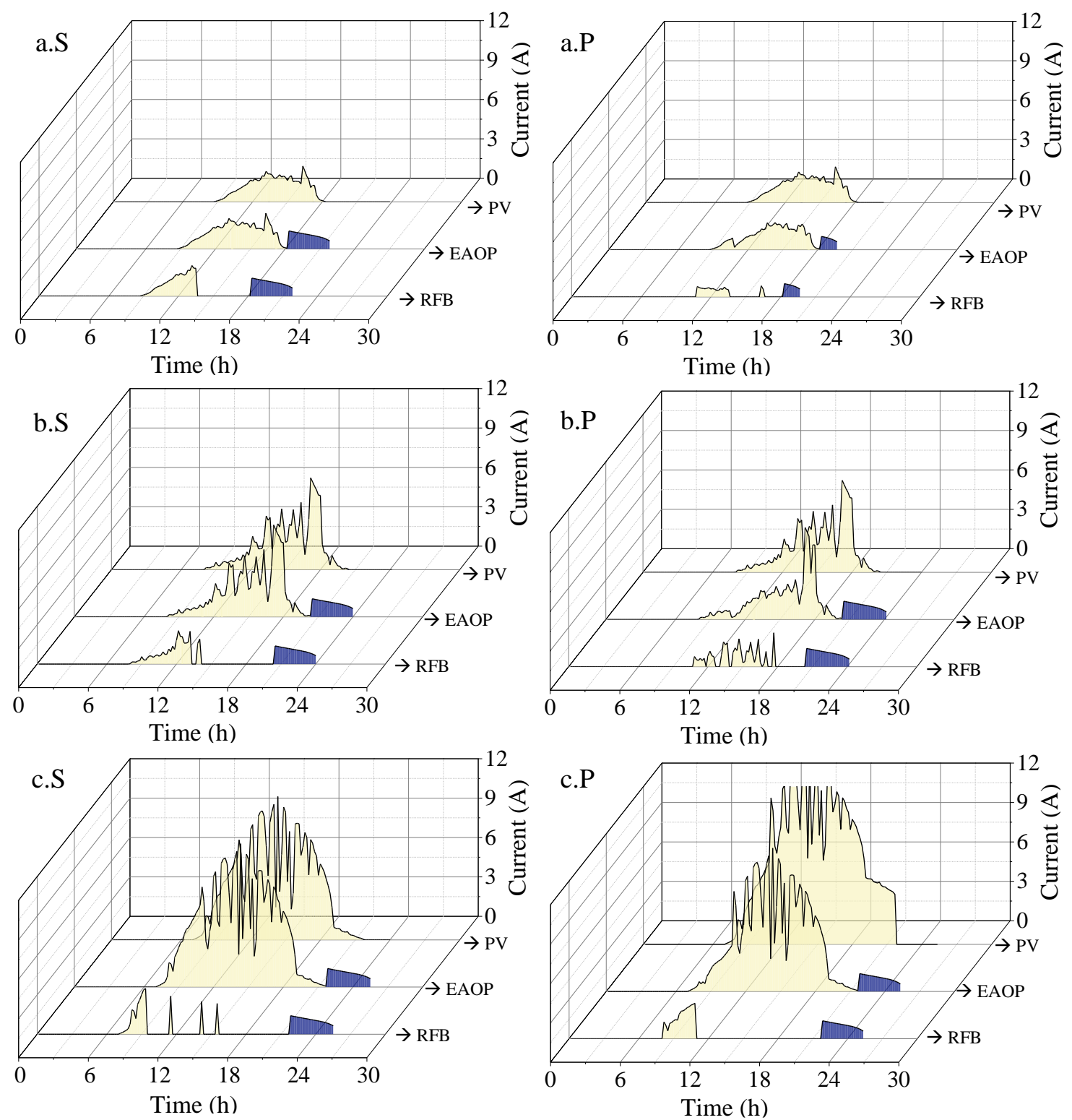

277

Figure 4. Current flows of the PV plant, the EAOP and the RFB stack under series (S) and parallel (P) electrical connections for the three cases of study ( $a, b$ and c Figure 2).

Daytime hours (yellow fill) and night hours (blue fill). 

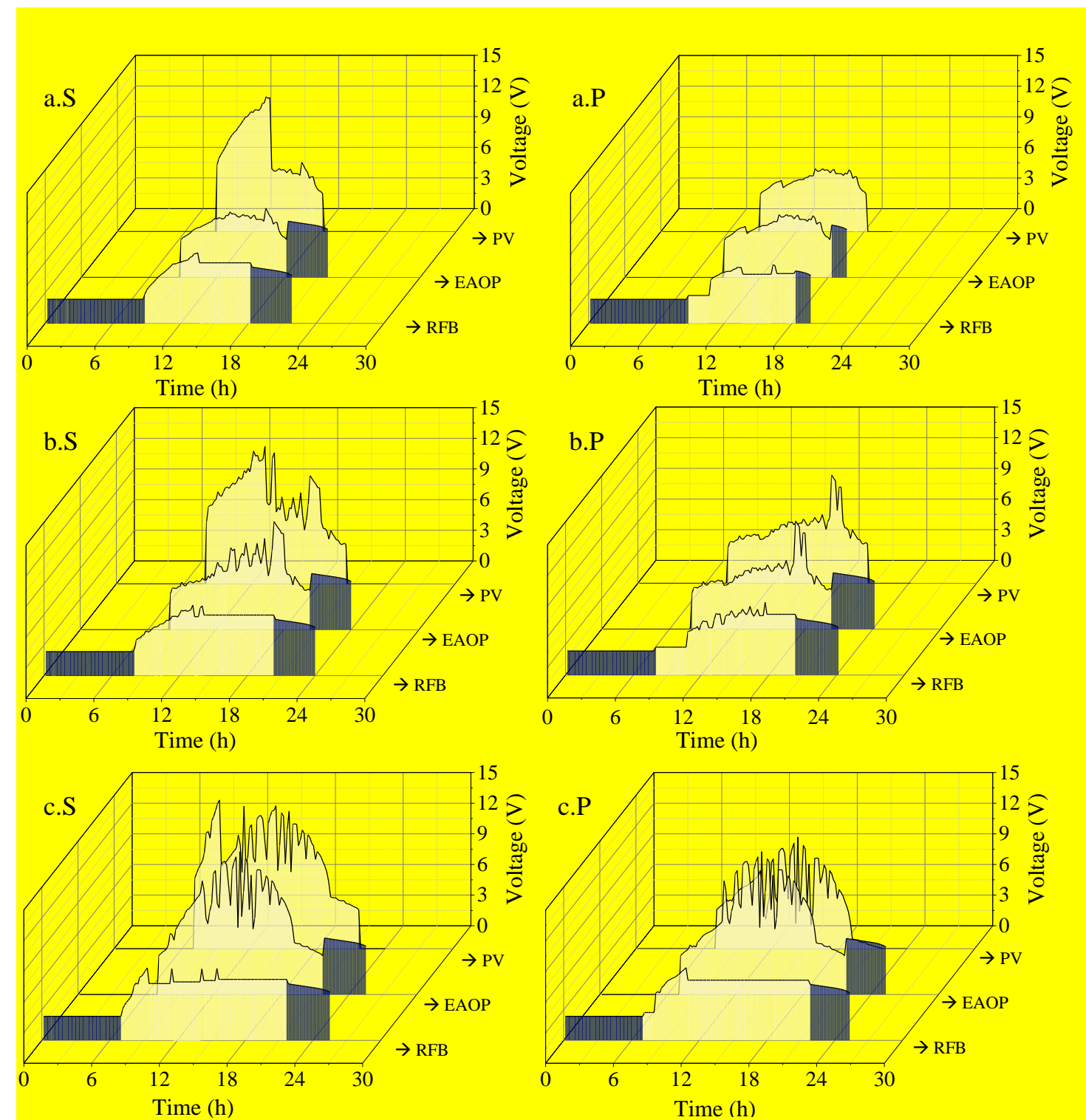

282

Figure 5. Voltage of the PV plant, the EAOP and the RFB stack under series (S) and parallel (P) electrical connections for the three cases of study ( $a, b$ and c Figure 2). Daytime hours (yellow fill) and night hours (blue fill). 
To evaluate this trend, charge and discharge capacities were quantified. In addition,

291

292

293

294

295

296

297

298

299

300

301

coulombic, voltage and energy efficiencies of the battery were calculated as reported elsewhere [67-69]. Those parameters allow to assess the overall performance of the battery when it is charged under different weather conditions and electrical configurations. Figure 6 shows the charge and discharge capacities, and the efficiencies of the battery under different operational conditions. As expected, the lower is the current density supplied to the RFB, the higher is the capacity stored into the battery. Thus, the higher capacities were noticed in Cases (a) and (b) because of the lower solar radiations received in those simulation tests. It must be highlighted that a slightly higher capacity was reached in Case (b) due to the lower solar radiation values observed during the first hour of the day. Conversely, the lowest capacities were observed in Case (c) because of the huge current densities powered in this case.
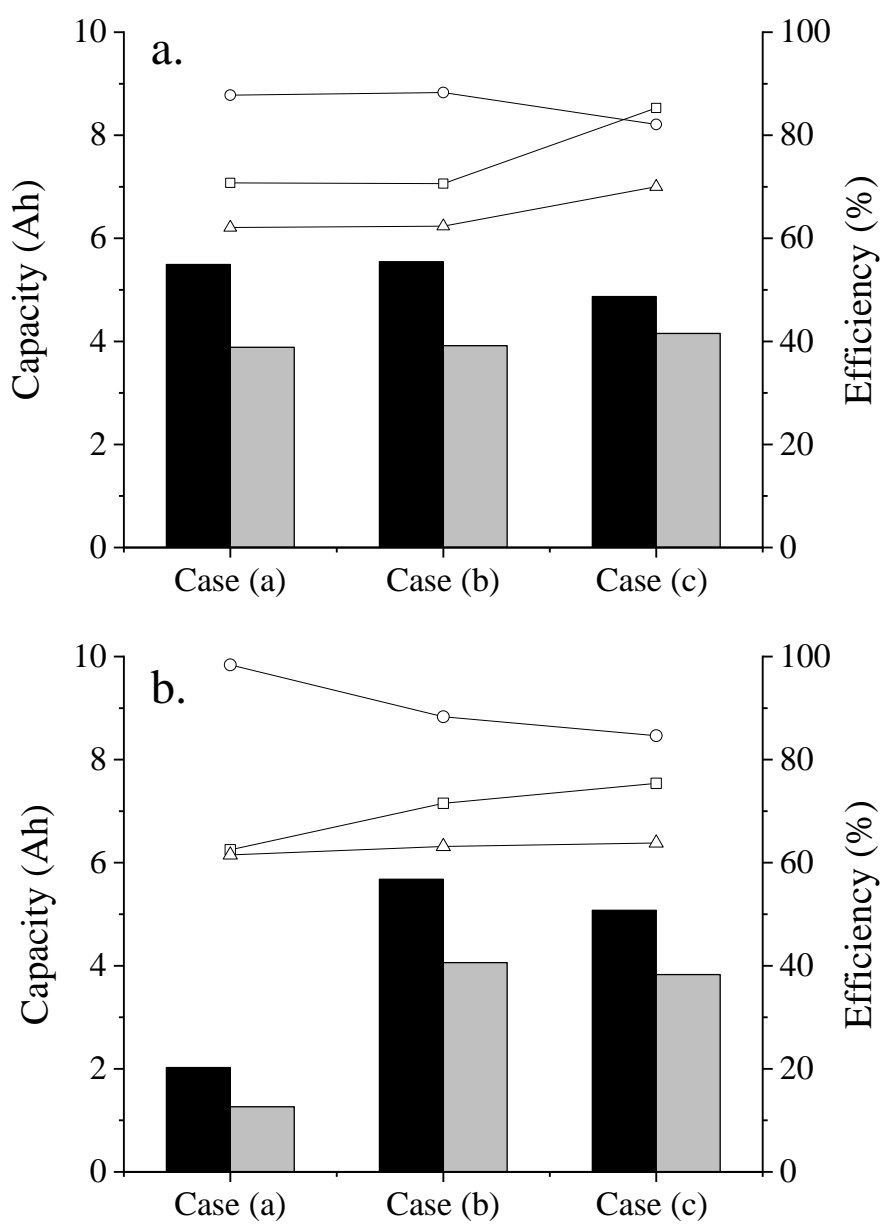
303 Figure 6. Charge (black bars) and discharge (grey bars) capacities. Coulombic ( $\square$ ), voltage $(\circ)$ and energy $(\triangle)$ efficiencies under a series (a) and parallel (b) powering.

Furthermore, it is important to note that higher capacities were observed using parallel connections. The lower current densities supplied under these powering strategies turned into higher capacities. Nevertheless, the power supplied in Case (a) was not enough to reach a full state of charge. Using this electrical connection, the battery only achieved an open circuit potential (OCP) of $4.87 \mathrm{~V}$. Conversely, the highest $\mathrm{OCP}$ was recorded in case (b) under parallel connection, $5.94 \mathrm{~V}$.

Regarding efficiencies, the higher coulombic efficiencies were observed when the charge steps were performed at higher current densities. Coulombic efficiencies losses can be caused by side reaction or cross mixing of electrolyte throughout the membrane $[70,71]$. The species crossover is mainly due to diffusion or migration forces [72]. Nevertheless, those phenomena were not considered into the RFB model outlined elsewhere [57]. Conversely, the voltage and energy efficiencies took lower values under those operational conditions. Higher voltage losses can be observed at higher current densities as a consequence of the higher ohmic overpotentials [69]. The same trend was noticed between series and parallel connections. The higher coulombic efficiencies were reported under series connections, because of the higher current densities supplied in this case. In contrast to that, the higher voltage and energy efficiencies were observed when the RFB and the EAOP worked under a parallel powering strategy.

Capacity and efficiencies values took values closer to other reported in literature where a RFB was used to store solar power under realistic conditions [44, 73]. Those results suggest again the huge robustness and accuracy of the RFB model previously proposed by our group as reported elsewhere [57]. 
327 Regarding discharge capacity results, longer remediation treatments could be performed when the battery stores a longer amount of energy. Contrary to expectation, the highest discharge capacities were observed under different electrical connection depending on the season of the year. In Case (b), the battery reached the highest discharge capacity under a parallel connection. Conversely, in Case (c) the battery was able to discharge a higher amount of energy when the electrochemical devices were connected in series. Those differences may be due to the different average current densities between charge and discharge steps, which may turn into different reaction speeds. This could explain the lower coulombic efficiencies obtained, regardless of the operational conditions and the case of study.

Many research groups reported the efficiency of an electrochemical remediation process according to the initial pollutant concentration and the current density supplied $[21,74$, 75]. At high organic concentrations, and low current densities, the pollutant is linearly mineralized following a kinetically controlled process. In contrast to that, at low contaminant concentrations and high current density values, the organic matter concentration drops exponentially, because of mass-transport limitations and side reactions of oxygen evolution. Furthermore, it is claimed that the remediation of concentrated wastewater effluents requires lower specific power consumptions $[76,77]$. Considering those premises, the removal of clopyralid was evaluated according to the power supplied to the electrooxidation reactor regarding the different powering strategies proposed. It is worth mentioning that the oxidation of clopyralid was evaluated according to Reaction 1 . This reaction points out that 18 electrons must be exchanged to mineralize the pollutant model of this study, clopyralid.

$\mathrm{C}_{6} \mathrm{H}_{3} \mathrm{Cl}_{2} \mathrm{NO}_{2}+10 \mathrm{H}_{2} \mathrm{O} \rightarrow 6 \mathrm{CO}_{2}+19 \mathrm{H}^{+}+\mathrm{NH}_{4}{ }^{+}+2 \mathrm{Cl}^{-}+18 \mathrm{e}^{-}$ 
The hydroxyl radical that are electrogenerated on the anode surface as Reaction 2 details, attack the pollutant until its complete oxidation up to $\mathrm{CO}_{2}$.

$$
\mathrm{H}_{2} \mathrm{O} \rightarrow \cdot \cdot \mathrm{OH}+\mathrm{H}^{+}+\mathrm{e}^{-}
$$

Figure 7 shows the specific clopyralid removal (total clopyralid removed per Ah) under a single PSEO and a PSEO assisted by a RFB by means of a series and parallel straightforward coupling. Figure 7 a shows the degradation attained without an energy storage system. In those cases, 54.43, 78.34 and $104.06 \mathrm{mg}$ were removed in Cases (a), (b) and (c), respectively. The longest summer day, and its higher solar radiation, are tied to higher remediation levels. According to the treatment time, the treatment was running $14.49 \mathrm{~h}$ during the summer day and only $9.33 \mathrm{~h}$ the winter day. The higher is the current supplied to the EAOP, the higher is the concentration of oxidants into the bulk solution which may favour the mineralization of organic matter [78].

Nevertheless, despite the total solar radiation received in Case (c) was 5.33 times higher than in Case (a), the remediation reached in the first case was only a $43.39 \%$ higher. Regarding the EAOP assisted by the RFB, results show higher remediations regardless the electrical connection used and the treatment day.

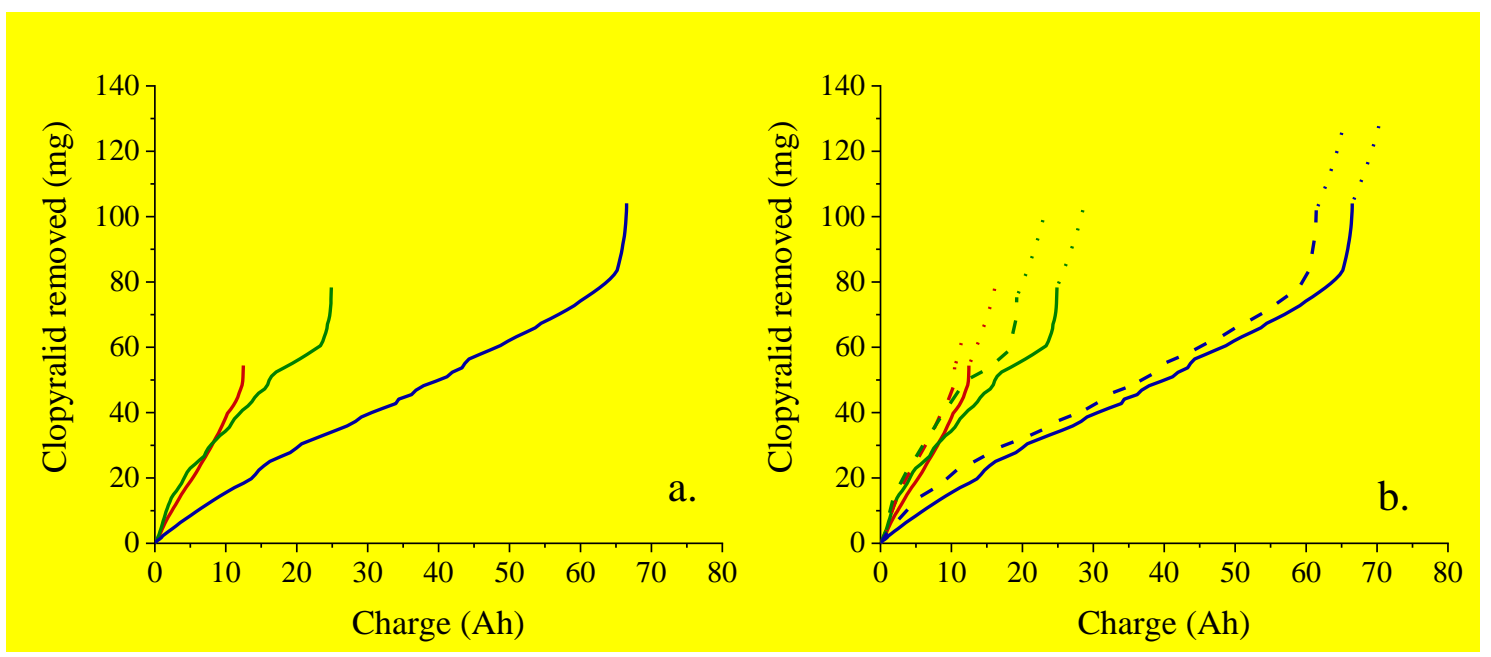


Figure 7. Total clopyralid removed under a EAOP powered by a PV plant without (a) and with (b) energy storage. PV powering: Series (solid line) and parallel (dashed line) electrical connections. RFB powering: dotted line. Case a (red), Case b (green) and Case c (blue).

Figure $5 \mathrm{~b}$ shows that the use of parallel electrical connections is slightly more efficient in all cases. Nevertheless, the increase of removal was almost the same once the RFB was used. The removal increases up to $48.30,33.94$ and a $68.37 \%$ when the battery was coupled in series. On the other hand, a 19.21, 31.56 and $64.13 \%$ of increase was observed 
397

398

best results were reached in Case (a), because of the lower current densities supplied by the PV panel, associated with the lower solar radiation received. Those results confirm again the higher efficiency of remediation treatments working at lower current densities.

Table 1. Removal of clopyralid per unit of energy supplied to the system.

\begin{tabular}{cccc}
\cline { 3 - 4 } & \multicolumn{3}{c}{ Removal $\left(\mathbf{m g ~ C l o p ~ W h}^{-1}\right)$} \\
\cline { 3 - 4 } & Without & \multicolumn{2}{c}{ With energy storage } \\
\cline { 3 - 4 } & storage & Series & Parallel \\
\hline Case (a) & 0.75 & 0.87 & 1.01 \\
Case (b) & 0.42 & 0.50 & 0.67 \\
Case (c) & 0.11 & 0.18 & 0.20 \\
\hline
\end{tabular}

According to the previous results, it can be claimed that working at lower current densities lead to more efficient remediations. Consequently, the use of a straightforward parallel connection could be an easier operational strategy to reach the most efficient remediation. This statement was also confirmed by other work reported by our group where the PSEO of a polluted effluent was carried out using a bench scale setup made up of two electrolysers [79]. The results reported removal of clopyralid between 0.48 and $2.52 \mathrm{mg}$ of clopyralid per Wh, being the remediation reached most efficient when both electrolyzers were connected in parallel to the PV plant. Thus, those results claimed that lower current densities, as a consequence of parallel connections, bring out efficient remediations and avoid the waste of green energy.

Once known that the parallel configuration leads to a higher remediation performance in terms of removal of pollutant per unit of energy, the influence of the initial pollutant concentration was assessed. To do that, predictive analyses were carried out by an initial pesticide concentration of 10 and $1000 \mathrm{mg} \mathrm{dm}^{-3}$. For comparative proposes, Case (b) was 
413 effluent was highly polluted, $1000 \mathrm{mg} \mathrm{dm}^{-3}$, reaching a removal of $2.05 \mathrm{mg}$ of clopyralid

414 per Wh. As expected, the lower the pollutant concentration, the lower the remediation

415 efficiency because of mass transfer problems may arise. Thus, only $0.09 \mathrm{mg}$ of clopyralid

416 per Wh were removed from the effluent polluted with $10 \mathrm{mg} \mathrm{dm}^{-3}$. These results claim

417 that the current supplied by the PV plant and the RFB to the EAOP and the initial pollutant concentration determine the efficiency of an EAOP.

419 To optimize the EAOP, the control of the current supplied to each device was assessed.

420 Figure 8 shows the removal of clopyralid per unit of energy supplied to the EAOP using 421 a targeted series or electrical connection. As the simulation planning exposed, a current 422 control may be carried out on the remediation treatment or on the battery. Under series 423 electrical connection, the electrochemical device that it is controlled undergoes a current 424 drop. Conversely, the other device is supplied in the same way than under a 425 straightforward series powering. In contrast to the current distribution in series, the use 426 of a controlled parallel powering strategy sends the exceeding energy supplied by the PV 427 panel to the electrochemical devices that is not controlled. Thus, this study allows to strike 428 a balance between the energy supplied to the EAOP and the RFB with the aim of reaching the most efficient remediation. 

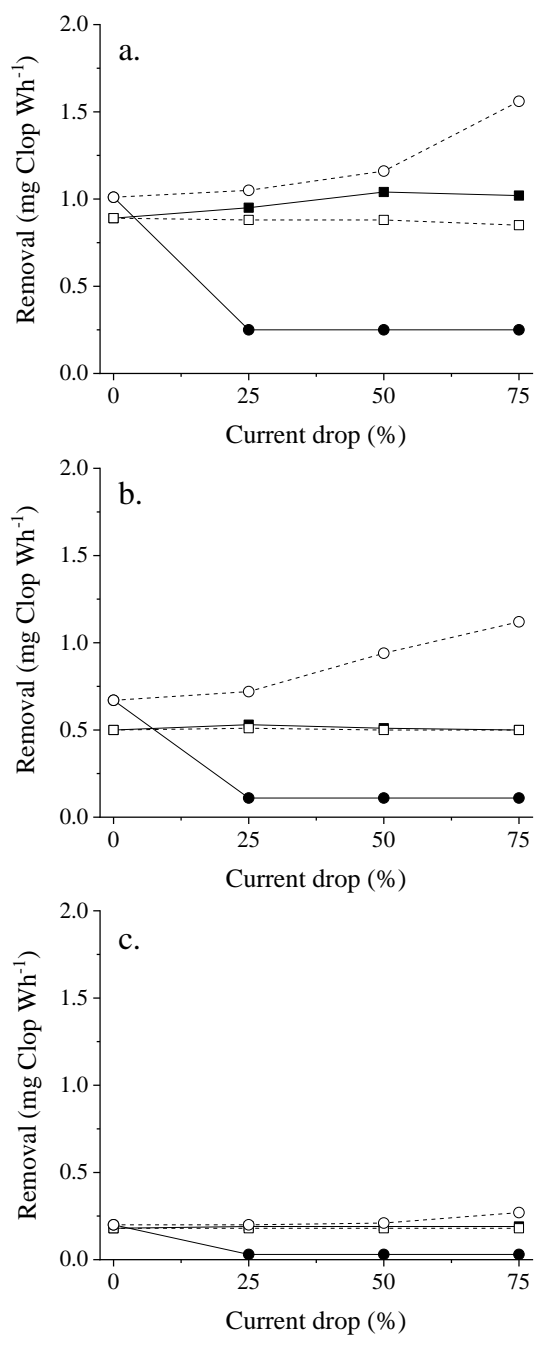

431 Figure 8. Removal per unit of energy supply. Series ( $\square$ ) and parallel (०) connection 432 between a EAOP and a RFB stack. EAOP (full symbol) or RFB (empty symbol) control. 433 Case (a); Case (b); Case (c).

434 Considering those premises, current drops of a 25,50 and $75 \%$ were simulated on each 435 electrochemical device, and under series and parallel connections, with the aim of 436 evaluating the most effective energy distribution capable of reaching the highest and most 437 efficient remediation. Furthermore, this prediction was performed for the three cases of 438 study previously exposed. Results show once again more efficient remediations when the 439 treatment worked at lower current densities, being this trend more prominent in Case (a). 
440 Regarding series connections, slight differences are observed. Nevertheless, higher 441 remediations are achieved under a EAOP control. As expected, the higher the current 442 drop, the higher the remediation quantified.

443 Those results confirm the lower efficiencies of EAOPs at higher current densities, because 444 of the waste of energy in secondary reactions [80]. It is important to highlight that a current drop to the EAOP, when the system works under parallel connection, does not allow the charge of the battery. The drop of current involves lower voltages values. Thus, considering that under parallel connection both devices have the same voltage, those values could be lower than the overvoltages of the battery which does not provide the electrical feature to carried out the RFB charge. Consequently, the removal reached in those cases is the same than when no energy storage systems are coupled to the EAOP. Simulation data noticed that less than a $10 \%$ of current drop allows the charge of the battery.

Furthermore, it is worth to mention that the EAOP process reaches the highest remediation when the system works under a parallel connection and an RFB control. The lower current densities supplied to the battery lead to higher capacities which extend the treatment time overnight and increase the total pollutant removal. The lower overvoltages reached at low current densities increase the charge voltage window of the battery which results into a higher capacity [81]. Consequently, the higher the energy stored, the longer the discharge time.

In short, it is important to highlight that predictive modelling is an innovative and promising tool able to optimize the operational condition of treatment in order to increase its performance and sustainability. 
464 From this work, the following conclusions can be drawn.

465

- The management of energy coming from a PV panel is key to ensure the power supply of an EAOPs coupled with green energy. Regulation of the solar power allows a smoother powering and consequently an efficient remediation. On the other hand, to store exceeded energy extends the treatment time.

- The coupling of a RFB noticeable increases the remediation reached regarding a single PSEO treatment without energy storage.

- The straightforward powering of a EAOP and an RFB by a PV plant can be performed under series and parallel connections. Results reported higher remediation values when both electrochemical devices are directly couped in parallel due to the lower current densities supplied to both systems which turn into higher overall performances.

- The green targeted powering allows an exhaustive control of the remediation and storage processes. Results suggest again that the use of a parallel connection under an RFB control aims to a higher remediation. The lower current densities supplied to the RFB points out higher capacities which extend the remediation treatment.

\section{Acknowledgments}

Financial support from the Spanish Agencia Estatal de Investigación through project PID2019-107271RB-I00 (AEI/FEDER, UE) is gratefully acknowledged. M. Millán thanks the UCLM for the predoctoral contract within the framework of the Plan Propio I+D.

\section{References}



Including the environmental criteria when selecting a wastewater treatment plant, Environ. Modell. Softw., 56 (2014) 74-82.

[2] UN, Report of the World Commission on Environment and Development: Our 490 Common Future, https://www.un.org/, 1987.

[3] F.C. Moreira, R.A.R. Boaventura, E. Brillas, V.J.P. Vilar, Electrochemical advanced oxidation processes: A review on their application to synthetic and real wastewaters, App. Catal., B, 202 (2017) 217-261.

[4] M.A. Rodrigo, N. Oturan, M.A. Oturan, Electrochemically Assisted Remediation of Pesticides in Soils and Water: A Review, Chem. Rev., 114 (2014) 8720-8745.

[5] C.A. Martinez-Huitle, E. Brillas, Electrochemical alternatives for drinking water disinfection, Angew. Chem. Int. Ed., 47 (2008) 1998-2005.

[6] K.R. Reddy, C. Cameselle, Electrochemical Remediation Technologies for Polluted Soils, Sediments and Groundwater, Wiley2009.

[7] J. Virkutyte, M. Sillanpää, P. Latostenmaa, Electrokinetic Soil Remediation - Critical

Overview, Sci. Total. Environ., 289 (2002) 97-121.

502

[8] P. Drogui, J.-F. Blais, G. Mercier, Review of Electrochemical Technologies for 503 Environmental Applications, Recent Pat. Eng., 1 (2007) 257-272.

504 [9] S. Vasudevan, M.A. Oturan, Electrochemistry: as cause and cure in water pollutionan overview, Environ. Chem. Lett., 12 (2014) 97-108. [10] A. Karaçali, M. Muñoz-Morales, S. Kalkan, B.K. Körbahti, C. Saez, P. Cañizares, M.A. Rodrigo, A comparison of the electrolysis of soil washing wastes with active and non-active electrodes, Chemosphere, (2019) 19-26. 
[11] M.A. Rodrigo, P. Cañizares, A. Sánchez-Carretero, C. Sáez, Use of conductive173-177.

[12] A.M. Polcaro, S. Palmas, F. Renoldi, M. Mascia, On the performance of Ti/SnO2 and $\mathrm{Ti} / \mathrm{PbO} 2$ anodes in electrochemical degradation of 2-chlorophenol for wastewater treatment, J. Appl. Electrochem., 29 (1999) 147-151.

[13] T. Muddemann, D. Haupt, M. Sievers, U. Kunz, Electrochemical Reactors for Wastewater Treatment, ChemBioEng Reviews, 6 (2019) 142-156.

[14] I. Sirés, E. Brillas, Remediation of water pollution caused by pharmaceutical residues based on electrochemical separation and degradation technologies: A review, Environ. Int., 40 (2012) 212-229.

[15] J.R. Dominguez, T. Gonzalez, P. Palo, J. Sanchez-Martin, M.A. Rodrigo, C. Saez, Electrochemical Degradation of a Real Pharmaceutical Effluent, Water Air and Soil Pollution, 223 (2012) 2685-2694.

[16] E.V. dos Santos, S.F.M. Sena, D.R. da Silva, S. Ferro, A. De Battisti, C.A. Martínez-

Huitle, Scale-up of electrochemical oxidation system for treatment of produced water generated by Brazilian petrochemical industry, Environ. Sci. Pollut. R., (2014).

[17] P.V. Nidheesh, M. Zhou, M.A. Oturan, An overview on the removal of synthetic dyes from water by electrochemical advanced oxidation processes, Chemosphere, 197 (2018) 210-227.

[18] C.A. Martínez-Huitle, E. Brillas, Decontamination of wastewaters containing synthetic organic dyes by electrochemical methods: A general review, App. Catal., B, 87 (2009) 105-145. 
[19] L. Bu, S. Zhu, S. Zhou, Degradation of atrazine by electrochemically activated persulfate using BDD anode: Role of radicals and influencing factors, Chemosphere, 195 (2018) 236-244.

[20] M.J. Martín de Vidales, M. Millán, C. Sáez, J.F. Pérez, M.A. Rodrigo, P. Cañizares, Conductive diamond electrochemical oxidation of caffeine-intensified biologically treated urban wastewater, Chemosphere, 136 (2015) 281-288.

[21] M.A. Rodrigo, P. Canizares, C. Buitron, C. Saez, Electrochemical technologies for the regeneration of urban wastewaters, Electrochim. Acta, 55 (2010) 8160-8164. Improving sustainability of electrolytic wastewater treatment processes by green powering, Sci. Total. Environ., 754 (2021).

[23] EPA, Introduction to Green Remediation, United States Environmental Protection

04/documents/grn_remed_epa-542-f-08-002.pdf, 2011.

[24] U. EPA, Green Remediation: Incorporating Sustainable Environmental Practices into Remediation of Contaminated Sites, U.S. Environmental Protection Agency, 2008. remediation of $\mathrm{Cu}$ polluted soil using a novel anode configuration, Electrochim. Acta, 181 (2015) 58-67.

551 [26] I. Hassan, Integrated solar electrokinetic remediation of heterogeneous soils 552 contaminated with copper, 2011. 
557 CDEO for the treatment of wastewater polluted with the herbicide 2,4-D, Chem. Eng. J., 277 (2015) 64-69.

[29] E. Alvarez-Guerra, A. Dominguez-Ramos, A. Irabien, Photovoltaic solar electrooxidation (PSEO) process for wastewater treatment, Chem. Eng. J., 170 (2011) 7-13. [30] J.M. Ortiz, E. Exposito, F. Gallud, V. Garcia-Garcia, V. Montiel, A. Aldaz, Photovoltaic electrodialysis system for brackish water desalination: Modeling of global process, J. Membr. Sci., 274 (2006) 138-149.

[31] M. Thomson, D. Infield, A photovoltaic-powered seawater reverse-osmosis system without batteries, Desalination, 153 (2003) 1-8.

[32] D. Valero, V. García-García, E. Expósito, A. Aldaz, V. Montiel, Electrochemical treatment of wastewater from almond industry using DSA-type anodes: Direct connection to a PV generator, Sep. Purif. Technol., 123 (2014) 15-22.

[33] D. Valero, J.M. Ortiz, E. Expósito, V. Montiel, A. Aldaz, Electrochemical Wastewater Treatment Directly Powered by Photovoltaic Panels: Electrooxidation of a Dye-Containing Wastewater, Envrion. Sci. Technol., 44 (2010) 5182-5187.

[34] D. Marmanis, K. Dermentzis, A. Christoforidis, K. Ouzounis, A. Moumtzakis, Electrochemical treatment of actual dye house effluents using electrocoagulation process directly powered by photovoltaic energy, Desalination Water Treat., 56 (2015) 29882993.

576 [35] M. Panizza, P.A. Michaud, G. Cerisola, C. Comninellis, Electrochemical treatment 577 of wastewaters containing organic pollutants on boron-doped diamond electrodes: 578 Prediction of specific energy consumption and required electrode area, Electrochem. 
580

581

582

583

584

585

586

587

588

589

590

591

592

593

594

595

596

597

598

599

600

601

602

[36] K. Iyappan, C.A. Basha, R. Saravanathamizhan, N. Vedaraman, C.A. Tahiyah Nou

Shene, S.N. Begum, Electrochemical treatment of tannery effluent using a battery integrated DC-DC converter and solar PV power supply--an approach towards environment and energy management, J. Environ. Sci. Health. A Tox. Hazard. Subst. Environ. Eng., 49 (2014) 1149-1162.

[37] M. Nisha Priya, K. Palanivelu, Electrochemical treatment of reactive dye effluent using solar energy, 2005.

[38] J.M. de Melo Henrique, D. de Andrade, E.L. Barros Neto, D.R. da Silva, E.V. dos Santos, Solar-powered BDD-electrolysis remediation of soil washing fluid spiked with diesel, J. Chem. Technol. Biotechnol., 94 (2019) 2999-3006.

[39] S. Ganiyu, L.R.D. Brito, E.C.T. De Araújo Costa, E.V. Dos Santos, C.A. MartínezHuitle, Solar photovoltaic-battery system as a green energy for driven electrochemical wastewater treatment technologies: Application to elimination of Brilliant Blue FCF dye solution, J. Environ. Chem. Eng., 7 (2019).

[40] H. Chen, T.N. Cong, W. Yang, C. Tan, Y. Li, Y. Ding, Progress in electrical energy storage system: A critical review, Prog. Nat. Sci., 19 (2009) 291-312.

[41] S. Bebelis, K. Bouzek, A. Cornell, M.G.S. Ferreira, G.H. Kelsall, F. Lapicque, C.P. de Leon, M.A. Rodrigo, F.C. Walsh, Highlights during the development of electrochemical engineering, Chem. Eng. Res. Des., 91 (2013) 1998-2020.

[42] W. Wang, Q. Luo, B. Li, X. Wei, L. Li, Z. Yang, Recent Progress in Redox Flow Battery Research and Development, Adv. Funct. Mater., 23 (2012) 970-986.

[43] F. Pan, Q. Wang, Redox Species of Redox Flow Batteries: A Review, Molecules, 20 (2015) 20499-20517. 
603

604

605

606

607

608

609

610

611

612

613

614

615

616

617

618

619

620

621

622

623

624

625

[44] R. López-Vizcaíno, E. Mena, M. Millán, M.A. Rodrigo, J. Lobato, Performance of a vanadium redox flow battery for the storage of electricity produced in photovoltaic solar panels, Renew. Energ., 114 (2017) 1123-1133.

[45] E. Mena, R. López-Vizcaíno, M. Millán, P. Cañizares, J. Lobato, M.A. Rodrigo, Vanadium redox flow batteries for the storage of electricity produced in wind turbines, Int. J. Energy Res., 42 (2018) 720-730.

[46] X. Shen, D. Lampert, S. Ogle, D. Reible, A software tool for simulating contaminant transport and remedial effectiveness in sediment environments, Environ. Modell. Softw., 109 (2018) 104-113.

[47] A. Urtiaga, C. Fernández-González, S. Gómez-Lavín, I. Ortiz, Kinetics of the electrochemical mineralization of perfluorooctanoic acid on ultrananocrystalline boron doped conductive diamond electrodes, Chemosphere, 129 (2015) 20-26.

[48] O. Scialdone, A. Galia, S. Randazzo, Electrochemical treatment of aqueous solutions containing one or many organic pollutants at boron doped diamond anodes. Theoretical modeling and experimental data, Chem. Eng. J., 183 (2012) 124-134.

[49] M. Panizza, A. Kapalka, C. Comninellis, Oxidation of organic pollutants on BDD anodes using modulated current electrolysis, Electrochim. Acta, 53 (2008) 2289-2295. [50] A.M. Polcaro, M. Mascia, S. Palmas, A. Vacca, Kinetic Study on the Removal of Organic Pollutants by an Electrochemical Oxidation Process, Ind. Eng. Chem. Res., 41 (2002) 2874-2881.

[51] A. Kapałka, G. Fóti, C. Comninellis, Kinetic modeling of the Electrochemical mineralization of organic pollutants for wastewater treatment, J. Appl. Electrochem., 38 (2008) 7-16. 
[52] M. Millán, M.A. Rodrigo, C.M. Fernández-Marchante, P. Cañizares, J. Lobato,

627 Powering with Solar Energy the Anodic Oxidation of Wastewater Polluted with Pesticides, ACS Sustain. Chem. Eng., 7 (2019) 8303-8309.

629

[53] M.R. Islam, F. Rahman, W. Xu, Advances in Solar Photovoltaic Power Plants, 630 Springer Berlin Heidelberg2016.

[54] W. Cao, Y. Hu, Renewable Energy: Utilisation and System Integration,

632

633

634

635

636

637

638

639

640

641

642

643

644

645

646

647

648
IntechOpen2016.

[55] J. Baeza, D. Gabriel, J. Lafuente, An expert supervisory system for a pilot WWTP, Environ. Modell. Softw., 14 (1999) 383-390.

[56] J. Guerrero, A. Guisasola, R. Vilanova, J.A. Baeza, Improving the performance of a WWTP control system by model-based setpoint optimisation, Environ. Modell. Softw., 26 (2011) 492-497.

[57] M. Millán, C.M. Fernández-Marchante, J. Lobato, P. Cañizares, M.A. Rodrigo, Modelling of the treatment of wastewater by photovoltaic solar electrochemical oxidation (PSEO) assisted by redox-flow batteries, Journal of Water Process Engineering, 40 (2021) 101974.

[58] W.R. Browne, Electrochemistry, Oxford University Press2018.

[59] S.N. Lvov, Introduction to Electrochemical Science and Engineering, Taylor \& Francis2014.

[60] A.H. Ltaïef, A. D'Angelo, S. Ammar, A. Gadri, A. Galia, O. Scialdone, Electrochemical treatment of aqueous solutions of catechol by various electrochemical advanced oxidation processes: Effect of the process and of operating parameters, J. Electroanal. Chem., 796 (2017) 1-8. 
[61] M.A. Oturan, J.-J. Aaron, Advanced Oxidation Processes in Water/Wastewater

650 Treatment: Principles and Applications. A Review, Crit. Rev. Env. Sci. Technol., 44

651

652

653

654

655

656

657

658

659

660

661

662

663

664

665

666

667

668

669

670

671

672 (2014) 2577-2641.

[62] M. Panizza, G. Cerisola, Direct And Mediated Anodic Oxidation of Organic Pollutants, Chem. Rev., 109 (2009) 6541-6569.

[63] Á. Cunha, J. Martins, N. Rodrigues, F.P. Brito, Vanadium redox flow batteries: a technology review, Int. J. Energy Res., 39 (2015) 889-918.

[64] K. Lourenssen, J. Williams, F. Ahmadpour, R. Clemmer, S. Tasnim, Vanadium redox flow batteries: A comprehensive review, J. Energy Storage, 25 (2019).

[65] M. Skyllas-Kazacos, M. Kazacos, State of charge monitoring methods for vanadium redox flow battery control, J. Power Sources, 196 (2011) 8822-8827.

[66] T. Jirabovornwisut, A. Arpornwichanop, A review on the electrolyte imbalance in vanadium redox flow batteries, Int. J. Hydrogen Energy, 44 (2019) 24485-24509.

[67] Y. Shi, C. Eze, B. Xiong, W. He, H. Zhang, T.M. Lim, A. Ukil, J. Zhao, Recent development of membrane for vanadium redox flow battery applications: A review, Appl. Energ., 238 (2019) 202-224.

[68] X. Ma, H. Zhang, C. Sun, Y. Zou, T. Zhang, An optimal strategy of electrolyte flow rate for vanadium redox flow battery, J. Power Sources, 203 (2012) 153-158.

[69] H.J. Lee, N.H. Choi, H. Kim, Analysis of Concentration Polarization Using UVVisible Spectrophotometry in a Vanadium Redox Flow Battery, J. Electrochem. Soc., 161 (2014) A1291-A1296.

[70] C. Blanc, A. Rufer, Understanding the Vanadium Redox Flow Batteries, 2010.

[71] D.-J. Park, K.-S. Jeon, C.-H. Ryu, G.-J. Hwang, Performance of the all-vanadium redox flow battery stack, J. Ind. Eng. Chem., 45 (2017) 387-390. 
673 [72] M. Moazzam, K. Oh, G. Gwak, H. Ju, Water crossover phenomena in all-vanadium 674 redox flow batteries, Electrochim. Acta, 297 (2019) 101-111.

675 [73] J. Lobato, E. Mena, M. Millán, Improving a Redox Flow Battery Working under 676 Realistic Conditions by Using of Graphene based Nanofluids, ChemistrySelect, 2 (2017) $6778446-8450$.

678 [74] M. Panizza, G. Cerisola, Application of diamond electrodes to electrochemical 679 processes, Electrochim. Acta, 51 (2005) 191-199.

680

[75] C. Comninellis, A. Kapalka, S. Malato, S.A. Parsons, L. Poulios, D. Mantzavinos, 681 Advanced oxidation processes for water treatment: advances and trends for R\&D, J. Chem. Technol. Biotechnol., 83 (2008) 769-776.

[76] G. Acosta-Santoyo, J. Llanos, A. Raschitor, E. Bustos, P. Cañizares, M.A. Rodrigo, Performance of ultrafiltration as a pre-concentration stage for the treatment of oxyfluorfen by electrochemical BDD oxidation, Sep. Purif. Technol., 237 (2020) 116366. a combined electrodialysis/electro-oxidation cell for the degradation of 2,4dichlorophenoxyacetic acid, Electrochim. Acta, 269 (2018) 415-421.

[78] A. Dominguez-Ramos, R. Aldaco, A. Irabien, Photovoltaic solar electrochemical 690 oxidation (PSEO) for treatment of lignosulfonate wastewater, J. Chem. Technol. Biotechnol., 85 (2010) 821-830.

[79] M. Millán, V.M. García-Orozco, J. Lobato, C.M. Fernández-Marchante, G. RoaMorales, I. Linares-Hernández, R. Natividad, M.A. Rodrigo, Toward more sustainable photovoltaic solar electrochemical oxidation treatments: Influence of hydraulic and 695 electrical distribution, J. Environ. Manage., 285 (2021).

696

[80] C. Comninellis, G. Chen, Electrochemistry for the Environment, Springer New 697 York2009. 
698 [81] X. Xi, X. Li, C. Wang, Q. Lai, C. Yuanhui, W. Zhou, C. Ding, Impact of Proton 699 Concentration on Equilibrium Potential and Polarization of Vanadium Flow Batteries, 700 ChemPlusChem, 80 (2015). 